\title{
Concepciones epistemológicas y didácticas de estudiantes avanzados del profesorado de educación primaria rural, en la provincia de Entre Ríos, Argentina.
}

\author{
Epistemological and educational conceptions by pre-service teachers teaching \\ in a rural primary school, Entre Ríos province, Argentina.
}

\author{
María Fernanda Zabalegui* \\ (iD) : https://orcid.org/0000-0003-4199-3291 \\ Ana Patricia Fabro** \\ (iD) : https://orcid.org/0000-0002-1761-4602
}

Doi: 10.17533/udea.unipluri.18.2.06

Cómo citar este artículo:

Zabalegui, M. F y Fabro, A. P (2018). Concepciones epistemológicas y didácticas de estudiantes avanzados del profesorado de educación primaria rural, en la provincia de Entre Ríos, Argentina. Uni-pluriversidad, 18(2), 87-101. https://doi.org/10.17533/udea.unipluri.18.2.06

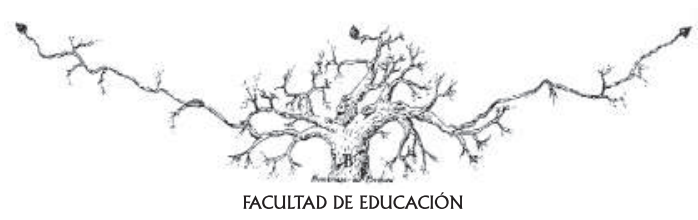

Recibido: 2018-08-31 • Aprobado: 2019-03-16

* Prof. en Ciencias Naturales. Prof. en Enseñanza de las Ciencias Superior. Magister en Didáctica de las Ciencias Experimentales. Coordinadora y docente de cátedra en la Universidad Autónomo de Entre Ríos. Contacto: fernandazabalegui@hotmail.com

** Bioquímica. Especialista en Docencia Universitaria; magister en Didácticas de la Ciencias Experimentales y en Docencia Universitaria. Doctora en Educación en Ciencias Experimentales. Docente e investigadora de Cátedra en la Universidad Nacional del Litoral de Santa Fe, Argentina. Directora y co-directora, participante en proyectos de investigación. Docente de posgrado de la maestría de Didáctica de las Ciencia Experimentales. Contacto: anapfabro@ hotmail.com 


\title{
Resumen
}

Se presentan los resultados de una investigación que tuvo como objetivos identificar y analizar las concepciones epistemológicas y didácticas de futuros profesores de educación en primaria rural, en relación con la enseñanza de las Ciencias Naturales, lo cual posibilitaría comprender las cosmovisiones que inciden, determinan y condicionan la toma de decisiones sobre el qué y el cómo enseñar. Para ello se analizan entrevistas y planificaciones de clases, las cuales se interpretan a la luz de diferentes categorías en torno a las concepciones epistemológicas absolutista, relativista y la epistemología de la complejidad; y dentro de las posturas didácticas en relación con las corrientes tradicional, tecnicista, espontaneísta o activa y modelos alternativos. Los resultados obtenidos permiten señalar que los estudiantes avanzados del profesorado de educación primaria con orientación rural poseen concepciones epistemológicas en construcción acerca del conocimiento científico que varían desde el absolutismo cuando son entrevistados, hasta el relativismo y la perspectiva de la complejidad cuando planifican sus clases. En tanto que las posturas didácticas son fuertemente activas, complementadas con posicionamientos problematizadores y por indagación, tanto en las entrevistas como en las planificaciones.

Palabras claves: concepciones epistemológicas, concepciones didácticas, estudiantes, educación rural.

\begin{abstract}
This research aimed to identify and analyze the epistemological and educational understandings by pre-service teachers of rural primary school in relation to the teaching of Natural Sciences. Therefore, this research would make possible to understand the world views that affect, define and determine the choices on what and how to teach. To this end, interviews and lesson plans are analyzed and interpreted taking account of different categories related to epistemological, absolutist or relative understandings and the epistemology of complexity. They are also analyzed within the educational approach in relation to the traditional, technical, spontaneous or active currents and alternative models. Results indicate that pre-service teachers of primary education with a rural training have epistemological understandings under construction about scientific knowledge. These understandings go from absolutism when they are interviewed, to relativism and perspective of complexity when they are planning their classes. Meanwhile, educational positions are strongly active and complemented by questions and inquiry, evidenced in both interviews and lesson plans.
\end{abstract}

Keys words: epistemological conceptions - didactic conceptions -student - rural education. 


\section{Introdução}

Desde la Didáctica de las Ciencias Naturales durante los últimos años se ha recobrado el interés por estudiar las concepciones que presentan los docentes al enseñar Ciencias Naturales (Ortega et al., 2014). Su estudio es de suma importancia, pues es el prisma cognitivo, metodológico y epistemológico a través del cual los docentes planifican y llevan a cabo sus prácticas educativas.

Gil y Rico (2003, p. 28) manifiestan que hablar de las concepciones de los docentes es referirse a "marcos organizadores, que tienen naturaleza cognitiva, y que condicionan la forma en que afrontan las tareas en el aula". Moreno y Azcárate (2003, p. 267), sostienen que en el interior de las concepciones se pueden encontrar "creencias, significados, conceptos, proposiciones, reglas, imágenes mentales, preferencias, etc., que influyen en lo que se percibe y en los procesos de razonamiento que se realizan"; argumentos que apoyan la importancia de investigar acerca de las concepciones de los docentes, pues éstas afectan la toma de decisiones en los procesos de planificación y ejecución de las propuestas de enseñanza.

A lo largo del tiempo se han utilizado diferentes términos para referirse a las concepciones de los docentes sobre la enseñanza, los más relevantes son: "creencias" (Pajares, 1992) y "teorías implícitas" (Pozo et al., 2006). El término "creencias" es definido como las construcciones psicológicas formadas por ideas, comprensiones, imágenes o proposiciones que se consideran verdaderas, que dirigen las acciones de las personas y actúan como guías para la interpretación de nuevas situaciones (Fernández Nistal et al., 2011).

Para Cossio Gutiérrez y Hernández Rojas (2016) las "teorías implícitas" son constelaciones complejas de conocimientos, las cuales se elaboran con fines pragmáticos de utilidad y que tienen como base la suma de experiencias personales dentro de determinados contextos culturales, con un papel causal, orientativo sobre las acciones y prácticas en las diferentes situaciones y contextos.

Otros autores como Sánchez (2001) establecen que las concepciones se relacionan con los marcos implícitos de conceptos que son esencialmente de naturaleza cognitiva. Es así que las concepciones se apoyan en las explicaciones lógicas, al mismo tiempo que se constituyen en un conjunto de conocimientos vinculados entre sí que dan respuestas a nuevos cuestionamientos, mediante la resignificación permanente.

En el campo de la enseñanza de las ciencias, Porlán (1993) alude a dos tipos de concepciones que giran en torno a cómo se percibe a la ciencia y al conocimiento científico; las de naturaleza epistemológica y las de carácter didáctico, que se orientan a identificar qué criterios tienen en cuenta los docentes para el desarrollo de sus clases de ciencias, qué sucede en las clases de ciencias, cómo enseñan y cómo creen que los estudiantes aprenden. 


\section{a) Perspectivas epistemológicas y didácticas:}

Diversas teorías epistemológicas a lo largo del tiempo han buscado sentido a estas cuestiones, por ejemplo el Absolutismo, el Relativismo y la Epistemología de la complejidad.

El Absolutismo recoge las tradiciones positivistas y racionalistas para las cuales el conocimiento científico es verdadero, universal y ahistórico. Para el Absolutismo el conocimiento es un producto de la mente humana forjado a partir de la razón, la lógica y la argumentación (Rodríguez y Adúriz Bravo, 2011). El conocimiento es jerarquizado, en el sentido de que la existencia de criterios racionales universales para la comprobación de las teorías asegura su veracidad y la posibilidad de delimitar la cientificidad de las mismas.

El método que se acepta como válido para la formulación de teorías es el método experimental de las ciencias naturales, para el cual el punto de partida es la observación imparcial de la realidad. Las observaciones son lo más objetivas posibles. La mente científica es como una hoja en blanco en la que se va escribiendo la experiencia acumulada (Rodríguez y Adúriz Bravo, 2011).

El Relativismo, por su parte, rechaza los postulados para la validación de las teorías y la visión de la ciencia que ésta asume. $\mathrm{Su}$ mentor, Thomas Kuhn, es quien ha formulado una crítica que constituye - usando su terminología - una "revolución conceptual". La perspectiva que propone el autor es histórica y social, con lo cual sus planteos han llevado a considerar elementos que habían estado ausentes en la filosofía de la ciencia hasta ese momento.

Para Khun (1997), las teorías científicas son estructuras complejas y las denomina "paradigmas", puesto que funcionan como modelos conceptuales de interpretación de la realidad aceptados por las comunidades científicas. En los períodos de vigencia incuestionable de un paradigma, o períodos de ciencia normal, los investigadores resuelven los enigmas o problemas que son susceptibles de solucionar a la luz del paradigma, mejorando su articulación y coherencia interna.

El cambio de paradigma se produciría en momentos de crisis en los cuales se da una reconstrucción del campo que conlleva a nuevos fundamentos, métodos y aplicaciones. Al partir de presupuestos distintos los paradigmas sucesivos serían incomparables. El cambio científico no es ya una cuestión de progreso lineal y acumulativo, por el contrario, es precedido por un profundo estado de crisis del paradigma dominante que desemboca en una revolución científica, ello da lugar al surgimiento de paradigmas alternativos de entre los cuales se impondrá aquel que consiga mayor adhesión entre los miembros de la comunidad científica.

\section{La Epistemología de la complejidad,} por su parte, es una postura alternativa formulada por Edgar Morin (2000) quien plantea que la ciencia requiere que sus explicaciones sean retroactivas y recursivas, no sólo causales y lineales, apareciendo la necesidad de contextualizar el conocimiento, es decir, de reconocer las interacciones del objeto con el entorno.

Dentro de sus ideas principales se sostiene que las partes se incluyen en el todo, pero el todo también en las partes, entendiendo así el concepto de totalidad; las explicaciones no deben ser reduccionistas sino de carácter heterogéneo y complementario, retroactivas y recursivas.

En las investigaciones se presenta la necesidad de relacionar los objetos y los su- 
jetos, el conocimiento requiere de una conceptualización que reconoce las interacciones de los objetos con el entorno. La complejidad da lugar a una forma de actuación compleja por la comunicación consciente entre ciencia, ética y política.

\section{Perspectivas didácticas:}

Por su parte, las perspectivas didácticas buscan, a lo largo del tiempo, construir alternativas válidas para los procesos de enseñanza y de aprendizaje en relación con las disciplinas específicas.

Porlán et al. (1998) y Solís Ramírez et al. (2012) proponen diversas miradas, perspectivas o modelos didácticos:

Modelo didáctico tradicional: en este enfoque la enseñanza se reduce a la transmisión de conocimientos, precisamente, de aquellos que se consideran verdades absolutas y permanentes. La concepción conservadora y transmisiva de las verdades conquistadas por nuestra cultura se apoyan en una concepción absolutista-racionalista del conocimiento, dado que, si bien reconoce el carácter provisorio de las teorías científicas, la justificación última de estas se encuentra en las ideas puras, universales e intemporales, que se sistematizan y formalizan lógicamente (Salvador Ibáñez, 2015).

Los contenidos están conformados por listados de temas, capítulos o unidades, en los que se organizan de manera exhaustiva y fragmentada para su posterior repetición por parte de los estudiantes. Su legitimidad y veracidad no se discute, puesto que su origen (los especialistas, la ciencia) constituye en sí mismo la condición de incuestionable.

El aprendizaje se produce por memorización y por recepción pasiva de infor- mación suministrada principalmente por el docente y el libro de texto. La estrategia de enseñanza predominante es la exposición o clase magistral, lo cual presenta el riesgo de caer en un verbalismo excesivo en detrimento de la experiencia vivida y de la actividad constructiva del alumno (Mayorga Fernández y Madrid Vivar, 2010).

La evaluación se concibe como una actividad de cierre en donde se aplican exámenes y se asignan calificaciones numéricas, que posibilitan comprobar los resultados, los cuales se traducen en cantidad de información memorizada. En este proceso se incluyen pruebas objetivas previas y finales como una forma eficaz de medir el grado de consecución de los objetivos previstos.

Modelo didáctico tecnicista: este enfoque expresa la aspiración de hacer de la enseñanza una actividad científica, rigurosa y eficaz. Surge en el contexto de la industrialización y del apogeo del capitalismo en el siglo pasado. Nace al amparo del eficientismo social que ve en la escuela y en el currículum un instrumento para lograr los productos que la sociedad y el sistema de producción necesitan en un momento dado. Los problemas escolares y la crisis de los sistemas educativos son vistos como fracasos de eficiencia de una sociedad competitiva, altamente tecnologizada, cuyos valores fundamentales son de orden económico (Gimeno Sacristán, 1992).

\section{Modelo didáctico espontaneísta o ac-} tivo: se enmarca en los postulados de la Escuela Nueva, corriente pedagógica que considera que la educación prepara para la vida, se da en la vida y coloca al estudiante en el centro de la reflexión. Sus principios son: actividad, libertad, individualidad, vitalidad, colectividad. Sus planteamientos iniciales coinciden con el desarrollo de la 
Psicología Evolutiva: sitúa al estudiante en el foco de la reflexión y en el centro de los procesos de enseñanza y de aprendizaje. El docente acompaña el proceso de desarrollo favoreciendo el cambio y la adquisición de habilidades, actitudes y valores.

Este enfoque se basa en la filosofía pedagógica de María Montessori que promueve formar a los alumnos para el mundo. Junto con John Dewey trabajaron en generar aportes para la pedagogía del niño, una pedagogía espontánea que destaca diferentes habilidades, como aprender haciendo y alimentando la curiosidad. Se propone una disciplina activa mediante la cual el alumno es el protagonista, es el que lidera su aprendizaje y toma la iniciativa a la hora de llevar a cabo sus tareas académicas (Támara Puerto, 2018).

Así, el conocimiento escolar es concebido como un producto abierto, generado a través de un proceso espontáneo de apropiación. La improvisación se convierte en una vía para dar respuesta a los requerimientos espontáneos que surgen en el aula. Los contenidos curriculares no se definen de manera apriorística, sino que se seleccionan a partir de los intereses de los alumnos vinculados a la resolución de problemas de la vida cotidiana. Las planificaciones son abiertas, flexibles y la improvisación no es una debilidad, sino una vía para dar respuestas a los requerimientos espontáneos del aula.

Modelos didácticos alternativos: estos enfoques constituyen una propuesta alternativa a las limitaciones de los enfoques anteriores, intenta superar la disociación entre teoría y práctica en la enseñanza, y recuperar una visión de conjunto de los estructurantes del método didáctico. Estos modelos de enseñanza se enmarcan dentro la didáctica constructivista y crítica. Propo- nen que el sujeto construya su conocimiento a través de la interacción con el entorno social, cultural y natural. La función del docente es mediar entre el contenido y los alumnos, proporcionando la ayuda necesaria para que el estudiante avance progresivamente hacia la apropiación significativa de los saberes.

La intervención docente cobra especial relevancia, en lo que hace tanto a su conocimiento disciplinar (que le permite decidir lo que es epistemológicamente relevante) como a su conocimiento metodológico, para enseñar el contenido específico. Las planificaciones tienen un carácter flexible y se van reformulando durante el proceso.

\section{b) ¿Por qué estudiar las concepciones epistemológicas y didácticas de los alumnos del Profesorado de Educación Primaria con orientación rural?}

Los relevamientos oficiales muestran en Argentina un número de doce mil escuelas primarias rurales, alcanzando el 50\% de las unidades educativas del total país (Galfrascoli et al., 2017). En la provincia Entre Ríos las escuelas rurales representan un $62 \%$ de las escuelas de la provincia (Panorama Educativo Rural Argentino, 2015).

A pesar del gran número de escuelas que se encuentran bajo esta modalidad, las investigaciones en torno a la enseñanza en la ruralidad son reducidas y en el caso de realizarse abordan aspectos sobre la tarea del maestro rural y la vinculación con el espacio social en el que se encuentra la escuela. Asimismo, se limitan a ofrecer orientaciones que se relacionan con el plano normativo, sin visibilizar lo que se realiza en las prácticas docentes y en los procesos de formación docente en la ruralidad (Brumat y Baca, 2015). 
Si nos enfocamos específicamente en la enseñanza de las Ciencias Naturales en el ámbito de la ruralidad, se torna más complejo aún encontrar referentes teóricos, existiendo solo algunas investigaciones en torno a estudios de casos en la Provincia de Santa Fe (Galfrascoli et al., 2013) relacionadas con las decisiones didácticas en torno a los contenidos de ciencias que abordan los docentes en ejercicio. La escasez de fuentes bibliográficas específicas a nivel nacional que analicen la enseñanza de las ciencias en las escuelas rurales es un obstáculo importante tanto para la formación inicial y continua, como también para los docentes en ejercicio en ese ámbito.

Por lo señalado consideramos importante investigar sobre estas temáticas porque permitirá analizar y comprender las cosmovisiones de los futuros docentes, las cuales podrían determinar y condicionar la toma decisiones sobre el qué y el cómo enseñar. Asimismo, su identificación y análisis posibilitará plantear acciones concretas en el campo de la Didáctica de las Ciencias Naturales que permitan repensar la formación docente en el ámbito de la ruralidad.

\section{Objetivos}

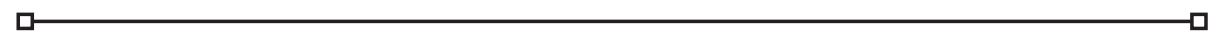

Identificar y analizar las concepciones sobre la enseñanza de las Ciencias Naturales do de Educación Primaria con orientación rural.

de los estudiantes avanzados del Profesora-

\section{Metodología}

\section{a) Población estudiada:}

Se trabajó con una población de diecisiete estudiantes avanzados que cursaron la asignatura Práctica III: "Aula y escuela: espacios para enseñar y aprender en el espacio social rural", durante el año 2016 de la Carrera de Profesorado en Educación Primaria con orientación rural de la Facultad de Humanidades, Artes y Ciencias Sociales de la Universidad Autónoma de Entre Ríos (sedes "Almafuerte" y "Alberdi").

\section{b) Enfoque metodológico:}

La investigación se enmarca dentro del modelo de investigación cualitativo o interpretativo, es decir, los datos son obtenidos dentro de un contexto natural y los significados se extraen a partir del análisis de la información brindada por los sujetos de la investigación. Ugalde Binda y
Balbastre Benave (2013) sostienen que las metodologías cualitativas se prefieren por sus propiedades explicativas y por su poder exploratorio. Estas ayudan a comprender la realidad social, porque dejan de lado las visiones reduccionistas que pretenden explicar, mediante datos cuantitativos, hechos sociales como la educación, para los cuales no existen leyes generalizadas, sino sentimientos, pensamientos e historias de los actores, que son captados a través de sus testimonios.

En el marco de las metodologías cualitativas se elige para esta investigación el "estudio de casos". Como una de sus fortalezas se destaca que posibilita el registro y descripción de los pensamientos, acciones y opiniones de las personas involucradas en el fenómeno estudiado. López Gónzalez (2013) señala que en este tipo de estudios se pueden obtener datos a través de diferentes fuentes 
tales como documentos, registros de archivos, entrevistas directas, planificaciones, observación de las clases y de las instalaciones.

\section{c) Instrumentos para la recolección de datos:}

\section{Instrumento $\mathrm{N}^{0}$ 1: Entrevistas.}

Para recolectar los datos se recurrió a las entrevistas semiestructuradas, las cuales presentan un grado de flexibilidad en sus preguntas, posibilitando ajustarlas a los sujetos entrevistados, aclarando términos, dudas o consultas.

Mediante estas entrevistas se buscó identificar las cosmovisiones de los estudiantes en torno a cómo conciben el conocimiento científico y la enseñanza de las Ciencias Naturales.

\section{Instrumento $\mathrm{N}^{0}$ 2: Planificaciones.}

Se analizaron las planificaciones escritas de los alumnos para las clases de práctica en las escuelas, las cuales reflejan las perspectivas epistemológicas y didácticas involucradas en su elaboración, en cuanto a la definición de los objetivos, el tratamiento de los contenidos (selección, secuencia y organización), la elaboración de estrategias de enseñanza, la toma de decisiones sobre los recursos de enseñanza, las formas de evaluación y la necesaria articulación entre los componentes de la misma. Se analizaron la presentación de los contenidos y la formulación de los objetivos con el fin de identificar concepciones epistemológicas; el tipo de actividades, los recursos didácticos y el tipo de evaluación que proponen a los fines de identificar y analizar diferentes concepciones didácticas.

Tabla $N^{\circ} 1$ : Instrumentos y categorías de análisis.

\begin{tabular}{|c|c|c|c|}
\hline \multicolumn{2}{|c|}{ Entrevistas (Instrumento $\mathrm{N}^{\circ} 1$ ) } & \multicolumn{2}{|c|}{ Planificaciones ( Instrumento $\mathbf{N}^{\circ} 2$ ) } \\
\hline Preguntas & $\begin{array}{l}\text { Categorías de análisis (desde } \\
\text { qué mirada epistemológica } \\
\text { responden) }\end{array}$ & $\begin{array}{l}\text { Aspectos a ana- } \\
\text { lizar }\end{array}$ & $\begin{array}{l}\text { Categorías de análisis (desde } \\
\text { qué mirada epistemológica } \\
\text { planifican) }\end{array}$ \\
\hline \multirow{4}{*}{$\begin{array}{l}\text { ¿Cómo puedes definir el } \\
\text { conocimiento científico? }\end{array}$} & Absolutismo & \multirow{16}{*}{$\begin{array}{l}\text { En relación a la } \\
\text { presentación de } \\
\text { los contenidos y } \\
\text { la formulación de } \\
\text { los objetivos. }\end{array}$} & Absolutismo \\
\hline & Relativismo & & Relativismo \\
\hline & Epistemología de la complejidad & & Epistemología de la complejidad \\
\hline & Otra perspectiva & & \multirow{13}{*}{ Otra perspectiva } \\
\hline \multirow{4}{*}{$\begin{array}{l}\text { ¿Cómo se produce el } \\
\text { conocimiento científico? }\end{array}$} & Absolutismo & & \\
\hline & Relativismo & & \\
\hline & Epistemología de la complejidad & & \\
\hline & Otra perspectiva & & \\
\hline \multirow{4}{*}{$\begin{array}{l}\text { ¿Cómo se valida el cono- } \\
\text { cimiento científico? }\end{array}$} & Absolutismo & & \\
\hline & Relativismo & & \\
\hline & Epistemología de la complejidad & & \\
\hline & Otra perspectiva & & \\
\hline \multirow{4}{*}{$\begin{array}{l}\text { ¿Desde qué perspectiva } \\
\text { epistemológica conside- } \\
\text { ras que es conveniente } \\
\text { planificar en la actuali- } \\
\text { dad las Ciencias Natura- } \\
\text { les? ¿Por qué? }\end{array}$} & Absolutismo & & \\
\hline & Relativismo & & \\
\hline & Epistemología de la complejidad & & \\
\hline & Otra perspectiva & & \\
\hline
\end{tabular}




\begin{tabular}{|c|c|c|c|}
\hline Preguntas & $\begin{array}{l}\text { Categorías de análisis (desde } \\
\text { qué mirada didáctica respon- } \\
\text { den) }\end{array}$ & $\begin{array}{l}\text { Aspectos a ana- } \\
\text { lizar }\end{array}$ & $\begin{array}{l}\text { Categorías de análisis (desde } \\
\text { qué mirada didáctica planif- } \\
\text { can) }\end{array}$ \\
\hline \multirow{5}{*}{$\begin{array}{l}\text { ¿Qué componentes tienes } \\
\text { en cuenta para la plani- } \\
\text { ficación de tus clases de } \\
\text { Ciencias Naturales en la } \\
\text { escuela rural? }\end{array}$} & Modelo tradicional & \multirow{5}{*}{$\begin{array}{l}\text { Actividades plani- } \\
\text { ficadas. }\end{array}$} & Modelo tradicional \\
\hline & Modelo tecnicista & & Modelo tecnicista \\
\hline & Modelo espontaneísta o activo & & Modelo espontaneísta o activo \\
\hline & Modelos alternativos & & Modelos alternativos \\
\hline & Otros modelos & & Otros modelos \\
\hline \multirow{5}{*}{$\begin{array}{l}\text { ¿Cómo desarrollas tus } \\
\text { clases de Práctica de } \\
\text { Ciencias Naturales en la } \\
\text { escuela rural? }\end{array}$} & Modelo tradicional & \multirow{5}{*}{$\begin{array}{l}\text { Recursos didác- } \\
\text { ticos que se pro- } \\
\text { ponen. }\end{array}$} & Modelo tradicional \\
\hline & Modelo tecnicista & & Modelo tecnicista \\
\hline & Modelo espontaneísta o activo & & Modelo espontaneísta o activo \\
\hline & Modelos alternativos & & Modelos alternativos \\
\hline & Otros modelos & & Otros modelos \\
\hline \multirow{5}{*}{$\begin{array}{l}\text { ¿Cómo realizas la eva- } \\
\text { luación en tus clases de } \\
\text { Ciencias Naturales en la } \\
\text { escuela rural? }\end{array}$} & Modelo tradicional & \multirow{10}{*}{$\begin{array}{l}\text { Evaluación pro- } \\
\text { puesta. }\end{array}$} & Modelo tradicional \\
\hline & Modelo tecnicista & & Modelo tecnicista \\
\hline & Modelo espontaneísta o activo & & Modelo espontaneísta o activo \\
\hline & Modelos alternativos & & Modelos alternativos \\
\hline & Otros modelos & & Otros modelos \\
\hline \multirow{5}{*}{$\begin{array}{l}\text { ¿Desde qué perspectiva } \\
\text { didáctica consideras que } \\
\text { es conveniente plani- } \\
\text { ficar en la actualidad } \\
\text { las Ciencias Naturales? } \\
\text { Fundamenta }\end{array}$} & Modelo tradicional & & \\
\hline & Modelo tecnicista & & \\
\hline & Modelo espontaneísta o activo & & \\
\hline & Modelos alternativos & & \\
\hline & Otros modelos & & \\
\hline
\end{tabular}

\section{Resultados:}

Se analizaron diecisiete entrevistas (a los diecisiete estudiantes participantes de la investigación) y las respectivas planificaciones de clases para implementar en las escuelas rurales. Los datos arrojados por estos instrumentos fueron analizados a partir de las categorías propuestas en la tabla $\mathrm{N}^{\mathrm{o}} 1$, según las distintas corrientes fundamentadas en la introducción teórica, que posibilitaron la identificación de las diferentes concepciones epistemológicas y didácticas de los estudiantes.

\section{a) Resultados obtenidos a partir del análisis de las entrevistas:}

En las respuestas de las entrevistas se observó que predominan posturas epistemo- lógicas enmarcadas con el Absolutismo (en nueve de diecisiete alumnos), considerando al conocimiento científico como una entidad o un producto acabado cuya verdad y validez son incuestionables, al tiempo que sostienen que al conocimiento científico se accede mediante la observación sistemática y la experimentación con el propósito de descubrir los principios o leyes que rigen la naturaleza, mediante el método científico. Como ejemplo de estas cosmovisiones se transcribe la siguiente expresión textual de una estudiante: "el conocimiento científico se valida a través de la realización de experimentos u observaciones que permiten confirmar las hipótesis que se plantean acerca de un problema estudiado". 
Se identificó, en un menor número de respuestas (en dos de diecisiete alumnos), la perspectiva relativista, expresada mediante ideas que sostienen que las teorías científicas son entendidas como estructuras complejas, los paradigmas, que funcionan como modelos conceptuales de interpretación de la realidad aceptados provisoriamente por las comunidades científicas. Como ejemplo de esas cosmovisiones expresan: "Puedo definir al conocimiento científico como el conjunto de ideas o saberes que pretenden comprender e interpretar los fenómenos naturales a través de diferentes estudios elaborando explicaciones provisorias".

También se registraron, en menor medida (dos de diecisiete alumnos), posturas relacionadas con la epistemología de la Complejidad, la cual sostiene que el conocimiento requiere de una conceptualización que reconoce las interacciones de los objetos con el entorno, afectado por factores éticos, sociales, históricos y políticos. Se observa en expresiones como: "El camino de producción del conocimiento comienza con muchas dudas, con los interrogantes que llevan a planear líneas e hipótesis de trabajo que desenvuelven toda una producción. Se trata de un trabajo colectivo, histórico, complejo continuo, problemático e interdisciplinar".

En otros casos se observaron posicionamientos combinados (dos de diecisiete alumnos) y en otros dos casos no se pudieron identificar las perspectivas epistemológicas.

En relación con los modelos didácticos, las respuestas de las entrevistas contemplan posturas didácticas activas o espontáneas (diez de diecisiete alumnos) mediante actividades que tienen estrecha relación con el contexto, priman salidas de campo o al patio de la escuela, la exploración del entorno de manera general, por ejemplo: buscando di- ferentes seres vivos (vegetales y animales). Se concibe al conocimiento escolar como un producto abierto, generado a través de un proceso espontáneo de apropiación, que tiene en cuenta la improvisación, el interés de los niños y las necesidades que surgen en el aula. Esta postura se observa en respuestas como: "Sin dudas el primer componente que tengo en cuenta a la hora de planificar o secuenciar una propuesta educativa es el contexto socioeducativo contemplando esa realidad escolar".

En algunas respuestas este modelo se encuentra asociado al modelo didáctico alternativo por indagación (cuatro de diecisiete estudiantes) y por indagación (tres de diecisiete estudiantes) a través propuestas que contemplan la resolución de problemas, la observación, la formulación de preguntas, la búsqueda de información en diversas fuentes bibliográficas, el análisis e interpretación de datos, la elaboración de conclusiones y la formulación de nuevas preguntas. Por ejemplo: "Parto del planteo de un problema que movilice a los alumnos y continúo con experiencias diversas, como las salidas de campo y experimentación”.

\section{b) Resultados obtenidos a partir del análisis de las planificaciones:}

En este punto se analizaron las planificaciones escritas elaboradas por los estudiantes. Se identificó que en cuanto a la presentación de los contenidos y a la formulación de los objetivos priman concepciones relativistas (doce de diecisiete estudiantes) mediante las cuales se concibe a la ciencia como verdad estable dentro del paradigma vigente. Se pudo determinar que la formulación de los contenidos, si bien es redactada por los estudiantes, es influenciada por la consulta que realizan de los Diseños 
Curriculares de Educación Primaria (2011), documento oficial para la educación de la provincia de Entre Ríos. En menor medida la epistemología de la complejidad: en tres casos no se pudo identificar las concepciones epistemológicas.

Respecto de las concepciones didácticas, en relación con el tipo de actividades propuestas, priman concepciones enmarcadas en los modelos didácticos espontaneístas o activos y alternativos por problemas. Por ejemplo, en contenidos como: "Propiedades de los materiales. Su comportamiento frente al calor" se plantean las siguientes actividades "Jana tiene tazas de distintos materiales y quiere elegir una para servir el té, pero no sabe cuál sería la más indicada para que sus amigas no se quemen las manos al tomarlo, como así también que se pueda conservar el té caliente mientras conversan ¿De qué materiales podrían ser las tazas" “Cuál de las tazas creen que debería elegir Jana?¿Por qué? ¿Cuál creen ustedes que se va a calentar primero? ¿Cuál creen que conservará más tiempo el té caliente?".
En cuanto a los recursos que proponen, priman los relacionados con los modelos didácticos alternativos a través del uso y manipulación de elementos de laboratorio, nuevas tecnologías, imágenes, diferentes fuentes bibliográficas, por ejemplo: "Se explorarán con los sentidos diferentes plantas de la huerta de la escuela, se utilizarán para la realización de experiencias diferentes semillas de la huerta, se implementarán los cuadernos de campo para los registros, se utilizarán textos informativos para interpretar los datos, se usarán las notebook para la realización de revistas digitales".

Respecto a la evaluación se reflejan posturas relacionadas con una evaluación de procesos que da cuenta del modelo didáctico espontaneísta o activo en expresiones como "Pensamos en una evaluación que contemple los procesos de aprendizaje atendiendo a las maneras de argumentar de los niños, decidir, relacionarse con el otro, a cómo hacen propio el contenido curricular".

Tabla No2: Concepciones epistemológicas y didácticas que predominan a partir de los resultados obtenidos de las entrevistas y análisis de las planificaciones.

\begin{tabular}{|c|l|l|l|l|}
\hline Alumno & $\begin{array}{l}\text { Concepción epis- } \\
\text { temológica (en- } \\
\text { trevistas iniciales) }\end{array}$ & $\begin{array}{l}\text { Concepciones epistemo- } \\
\text { lógicas (Observadas en } \\
\text { las planificaciones) }\end{array}$ & $\begin{array}{l}\text { Concepciones didác- } \\
\text { ticas (entrevistas ini- } \\
\text { ciales) }\end{array}$ & $\begin{array}{l}\text { Concepciones didácticas } \\
\text { (Observadas en las planifi- } \\
\text { caciones) }\end{array}$ \\
\hline 1 & Relativismo & $\begin{array}{l}\text { No se puede identificar } \\
\text { una concepción. }\end{array}$ & $\begin{array}{l}\text { Modelo espontaneísta o } \\
\text { activo y alternativos (por } \\
\text { indagación). }\end{array}$ & $\begin{array}{l}\text { Modelo espontaneísta o activo } \\
\text { y alternativos (por problemas). }\end{array}$ \\
\hline 2 & $\begin{array}{l}\text { Epistemología de } \\
\text { la complejidad }\end{array}$ & $\begin{array}{l}\text { Epistemología de la com- } \\
\text { plejidad }\end{array}$ & $\begin{array}{l}\text { Modelo espontaneísta o } \\
\text { activo y alternativos (por } \\
\text { indagación). }\end{array}$ & $\begin{array}{l}\text { Modelo espontaneísta o activo } \\
\text { y alternativos (por problemas). }\end{array}$ \\
\hline 3 & Absolutismo & $\begin{array}{l}\text { Epistemología de la com- } \\
\text { plejidad }\end{array}$ & $\begin{array}{l}\text { Modelo espontaneísta o } \\
\text { activo. }\end{array}$ & $\begin{array}{l}\text { Modelo espontaneísta o activo } \\
\text { y alternativos (por problemas). }\end{array}$ \\
\hline 4 & Absolutismo & Relativismo & $\begin{array}{l}\text { Modelo espontaneísta } \\
\text { o activo y alternativos } \\
\text { (problematizador). }\end{array}$ & $\begin{array}{l}\text { Modelo espontaneísta o activo } \\
\text { y alternativos (por problemas). }\end{array}$ \\
\hline 5 & Absolutismo & Relativismo & $\begin{array}{l}\text { Modelo espontaneísta o } \\
\text { activo y alternativos (por } \\
\text { indagación). }\end{array}$ & $\begin{array}{l}\text { Modelo espontaneísta o activo } \\
\text { y alternativos (por problemas). }\end{array}$ \\
\hline
\end{tabular}




\begin{tabular}{|c|c|c|c|c|}
\hline Alumno & $\begin{array}{l}\text { Concepción epis- } \\
\text { temológica (en- } \\
\text { trevistas iniciales) }\end{array}$ & $\begin{array}{l}\text { Concepciones epistemo- } \\
\text { lógicas (Observadas en } \\
\text { las planificaciones) }\end{array}$ & $\begin{array}{l}\text { Concepciones didác- } \\
\text { ticas (entrevistas ini- } \\
\text { ciales) }\end{array}$ & $\begin{array}{l}\text { Concepciones didácticas } \\
\text { (Observadas en las planifi- } \\
\text { caciones) }\end{array}$ \\
\hline 6 & Absolutismo & $\begin{array}{l}\text { No se puede identificar } \\
\text { una concepción. }\end{array}$ & $\begin{array}{l}\text { Modelo espontaneísta o } \\
\text { activo }\end{array}$ & $\begin{array}{l}\text { Modelo espontaneísta o activo } \\
\text { y alternativos (por problemas). }\end{array}$ \\
\hline 7 & Absolutismo & Relativismo & $\begin{array}{l}\text { Modelo espontaneísta o } \\
\text { activo }\end{array}$ & Modelo espontaneísta o activo \\
\hline 8 & Absolutismo & Relativismo & $\begin{array}{l}\text { Modelo espontaneísta o } \\
\text { activo }\end{array}$ & Modelo espontaneísta o activo \\
\hline 9 & Absolutismo & Relativismo & $\begin{array}{l}\text { Modelo espontaneísta o } \\
\text { activo }\end{array}$ & $\begin{array}{l}\text { Modelo espontaneísta o activo } \\
\text { y alternativos (por problemas). }\end{array}$ \\
\hline 10 & Absolutismo & $\begin{array}{l}\text { No se puede identificar } \\
\text { una concepción. }\end{array}$ & $\begin{array}{l}\text { Modelo espontaneísta o } \\
\text { activo y alternativos (por } \\
\text { indagación). }\end{array}$ & $\begin{array}{l}\text { Modelo espontaneísta o activo } \\
\text { y alternativos (por problemas). }\end{array}$ \\
\hline 11 & Absolutismo & Relativismo & $\begin{array}{l}\text { Modelo espontaneísta o } \\
\text { activo }\end{array}$ & $\begin{array}{l}\text { Modelo espontaneísta o activo } \\
\text { y alternativos (por problemas). }\end{array}$ \\
\hline 12 & $\begin{array}{l}\text { Epistemología de } \\
\text { la complejidad }\end{array}$ & Relativismo & $\begin{array}{l}\text { Modelo espontaneísta } \\
\text { o activo y alternativos } \\
\text { (problematizador). }\end{array}$ & $\begin{array}{l}\text { Modelo espontaneísta o activo } \\
\text { y alternativos (por problemas). }\end{array}$ \\
\hline 13 & $\begin{array}{l}\text { Absolutismo/rela- } \\
\text { tivismo }\end{array}$ & Relativismo & $\begin{array}{l}\text { Modelo espontaneísta } \\
\text { o activo y alternativos } \\
\text { (problematizador). }\end{array}$ & $\begin{array}{l}\text { Modelo espontaneísta o activo } \\
\text { y alternativos (por problemas). }\end{array}$ \\
\hline 14 & Relativismo & Relativismo & $\begin{array}{l}\text { Modelo espontaneísta o } \\
\text { activo }\end{array}$ & Modelo espontaneísta o activo \\
\hline 15 & $\begin{array}{l}\text { Relativismo/Epis- } \\
\text { temología de la } \\
\text { complejidad }\end{array}$ & Relativismo & $\begin{array}{l}\text { Modelo espontaneísta o } \\
\text { activo }\end{array}$ & Modelo espontaneísta o activo \\
\hline 16 & $\begin{array}{l}\text { No se puede iden- } \\
\text { tificar. }\end{array}$ & Relativismo & $\begin{array}{l}\text { Modelo espontaneísta o } \\
\text { activo }\end{array}$ & Modelo espontaneísta o activo \\
\hline 17 & $\begin{array}{l}\text { No se puede iden- } \\
\text { tificar. }\end{array}$ & Relativismo & $\begin{array}{l}\text { Modelo espontaneísta o } \\
\text { activo }\end{array}$ & Modelo espontaneísta o activo \\
\hline
\end{tabular}

\section{Discusión y conclusiones:}

Los resultados obtenidos permiten señalar que los estudiantes avanzados del Profesorado de Educación Primaria con orientación rural poseen concepciones epistemológicas en construcción acerca del conocimiento científico que varían principalmente desde el Absolutismo cuando son entrevistados, hasta el Relativismo y la Epistemología de la Complejidad cuando planifican sus clases. En tanto que las posturas didácticas son fuertemente activas, complementadas con posicionamientos desde modelos alternativos problematizadores y por indagación, tanto en las entrevistas como en las planificaciones.
Si se comparan los datos obtenidos en las entrevistas con investigaciones realizadas en Latinoamérica, se encuentran algunas coincidencias con el trabajo de Gallego Quiceno et al. (2017) que estudió con una población de trescientos cincuenta estudiantes de los primeros y últimos años de los profesorados afines a las Ciencias Naturales de la Universidad de Antioquia (Colombia) con la cual aplican el inventario de Creencias Pedagógicas y Científicas de Profesores confeccionado por Porlán et al., (1997) y muestra que en la población estudiada priman concepciones epistemológicas empírico-positivo-inductivistas sobre la ciencia. 
También coincide con el trabajo de Silva et al., (2014) que señala que en la formación docente de ciencias de Brasil predominan los enfoques epistemológicos positivistas que persisten junto a otros posicionamientos identificados con corrientes epistemológicas pos-positivistas.

En cuanto a las posturas didácticas en las entrevistas predominan las relacionadas con los modelos didácticos espontaneístas o activo y alternativos (por problematización e indagación). Estos datos se contraponen a los obtenidos por Demuth Mercado y Alcalá (2009) sobre concepciones de docentes y estudiantes del Instituto de Formación Docente Dr. Juan Pujol de la ciudad de Corrientes, que señalan que las concepciones didácticas reflejan modelos tradicionales de enseñanza, concibiendo a la enseñanza como la transmisión de conocimientos y posicionando al docente como trasmisor y al alumno como sujeto pasivo.

Respecto a las posturas epistemológicas identificadas en las planificaciones predominan las posturas relativistas y los modelos didácticos espontaneísta o activos y alternativos (por problemas). En este punto se encuentran diferencias respecto al trabajo de Montenegro (2013) en la formación de docentes de escuelas primaria de la ciudad de La Plata (Argentina) que muestra que los docentes planifican desde una perspectiva epistemológica absolutista y modelos de enseñanza tradicionales, como también con el de Fabro et al. (2016) en Santa Fe (Argentina) que revela que a la hora de planificar las clases de ciencia los estudiantes la realizan desde modelos didácticos tradicionales.

Los resultados obtenidos también permiten coincidir con Acevedo et al., (2013) quienes sostienen que a lo largo de las situaciones de enseñanza es posible que los futuros docentes expresen diferentes visiones vinculadas no solamente con las concepciones que tienen acerca de cómo funciona la ciencia, sino también con la formación docente recibida, con su historia escolar, con enfoques didácticos presentes en la enseñanza, como también con los recursos editoriales disponibles.

El trabajo realizado posibilitó identificar y analizar las concepciones epistemológicas y didácticas de los futuros docentes, a los fines poder generar intervenciones que posibiliten contribuir a repensar la formación docente desde acciones que tengan en cuenta la imagen de la ciencia y sus modos de enseñarla.

\section{REFERENCIAS BIBLIOGRÁFICAS}

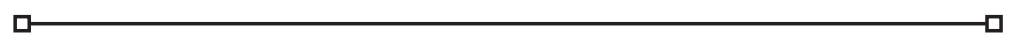

Acevedo, C., Porro, S. y Adúriz-Bravo, A. (2013). Concepciones epistemológicas, enseñanza y aprendizaje en la clase de ciencias. TED, 34, 29-46.

Brumat, M. R. y Baca, C. (2015). Prácticas Docentes en contextos de ruralidad. Un estudio en escuelas rurales del Norte de Córdoba. Educación, Formación e Investigación,.1(2), 1-15.

Consejo General de Educación (2011). Diseño Curricular de Educación Primaria Ciencias Naturales. Recuperado de: https://www.entrerios.gov.ar/CGE/normativas/resoluciones_cge/2014/417014_CGE_Disenio_Curricular_para_la_Formacion_Docente_de_Educacion_Primaria.pdf 
Cossio, E. F. y Hernández, G. (2016). Las teorías implícitas de enseñanza y aprendizaje de profesores de primaria y sus prácticas docentes. Revista Mexicana de Investigación Educativa, 21(71), $1135-1164$.

Demuth, P. y Alcalá, M. T. (invest.), y Graciela, M. (coord.). (2009). Concepciones epistemológicas y didácticas de docentes y futuros docentes de educación primaria. Análisis de caso. Buenos Aires, Argentina: Ministerio de Educación de la Nación.

Fabro, A., Galfrascoli, A., Lederhos, M., López, C., Nóbile, L., Odetti, H., Veglia, S. y Vénica, M. (2016). Análisis de las prácticas de enseñanza de Ciencias Naturales de alumnos residentes del Profesorado de Educación Primaria de la Provincia de Santa Fe, Argentina. Uni-pluri/versidad, 16(1), 64-75.

Fernández Nistal, M. T., Pérez, R. E., Peña, S. H. y Mercado, S. M. (2011). Concepciones sobre la enseñanza del profesorado y sus actuaciones en clases de ciencias naturales de educación secundaria. Revista Mexicana de Investigación Educativa, 16(49), 571-596.

Galfrascoli, A., Lederhos, M., y Veglia, S. (2013). Las decisiones didácticas de los docentes de Ciencias Naturales en grados agrupados en el contexto de ruralidad Estado de avance de una Investigación Educativa. Revista Aula Universitaria, 15, 119-126.

Galfrascoli, A., Lederhos, M. y Veglia, S. (2017). Prácticas Educativas en Educación rural: Enseñanza de las Ciencias Naturales. Revista Investigación e innovación educativa, 93, 43-57.

Gallego, D., Bustamante, L., Gallego, L., Salcedo, L., Gava, M. y Alfaro, E. (2017). Estudio cuantitativo sobre las concepciones de ciencia, metodología y enseñanza para profesores en formación. Revista Lasallista de Investigación, 14(1), 144-161.

Gil, D. y Rico, L. (2003). Concepciones y creencias del profesorado de secundaria sobre enseñanza y aprendizaje de las matemáticas. Investigación Didáctica, 21, 27-47.

Gimeno, J. (1982). La pedagogía por objetivos. Obsesión por la eficiencia. Madrid, España: Morata.

Kuhn, T. (1997). La estructura de las revoluciones cientificas. Ciudad de México, México: Fondo de Cultura Económica.

López, W. O. (2013). El estudio de casos: una vertiente para la investigación educativa. Revista Venezolana de Educación, 17(56), 139-144.

Mayorga, M. J. y Madrid, D. (2010). Modelos didácticos y Estrategias de enseñanza en el Espacio Europeo de Educación Superior. Tendencias pedagógicas, 15(1), 91-111.

Montenegro, E. (2013.) Prácticas de Planificación en Ciencias Naturales de docentes de Escuela Primaria. La Plata, Argentina: Facultad de Humanidades y Ciencias de la Educación (FaHCE) de la Universidad Nacional de La Plata.

Morín, E. (2000). Los siete saberes necesarios para la educación del futuro. Paris, Francia: Santillana.

Moreno, M. y Azcarate, C. (2003). Concepciones y creencias de los profesores universitarios de matemáticas acerca de la enseñanza de las ecuaciones diferenciales. Enseñanza de las ciencias, 21(2), 265-280. 
Ortega, F., Márquez, C. y Tamayo, E. (2014). Cambio en las concepciones de los docentes sobre la argumentación y su desarrollo en clase de ciencias. Enseñanza de las Ciencias, 32, 53-70.

Pajares, M. F. (1992). Teachers' beliefs and educational research: Cleaning up a messy construct. Review of Educational Research, 62, 307-332.

Porlán, R. (1993). Constructivismo y escuela. Hacia un modelo de enseñanza- aprendizaje basado en la investigación. Serie Fundamentos, 4. Madrid, España: Diada Editorial.

Porlan, R., Rivero, A. y Martín del Pozo, R. (1997). Conocimiento Profesional y epistemología de los profesores I: teoría, métodos e instrumentos. Enseñanza de las Ciencias, 15(2), 155-171.

Porlán, R., Rivero, A., y Martín del Pozo, R. (1998). Conocimiento profesional y epistemología de los profesores, II: estudios empíricos y conclusiones. Citado en: Porlán, R., Martín del Pozo, R., Rivero, A., Harres, J., Azcárate, P. y Pizzato, M. (2011). El cambio del profesorado de ciencias II: Itinerarios de progresión y obstáculos en estudiantes de magisterio. Enseñanza de las ciencias, 29(3), 353-370.

Pozo, J. I., Scheuer, N., Mateos, M., Pérez, M. P., Ortega, E. y Monserrat, D. (2006). Nuevas formas de pensar la enseñanza y el aprendizaje. Barcelona, España: Grao.

Rodríguez, R. y Adúriz, A. (2011). ¿A qué epistemología recurrir para investigar sobre la enseñanza de las ciencias? Revista EDUCyT, 3, 3-18.

Salvador, A. M. (2015). Enseñanza de la Biología y Geología a través de aprendizaje basado en problemas (Tesis de Maestría). Universidad de Valladolid, Valladolid, España.

Sánchez, L. (2001). Concepciones sobre enfoques asociacionista y constructivista del aprendizaje de docentes universitarios y profesionales no docentes. Revista Iberoamericana de Educación, 1-22. Recuperado de: file://C:/Users/jesus/Downloads/377Sanchez.PDF

Solís, E., Porlán, R. y Rivero, A. (2012). ¿Cómo representar el Conocimiento Curricular de los profesores de Ciencias y su evolución? Enseñanza de las Ciencias, 30, 9-30.

Silva, P., Fabro, A. P y Santos Duarte, A. C. (2014). Reflexiones en relación con las influencias del pensamiento positivista y pospositivista en la formación de profesores de Ciencias en Brasil. Revista Aula Universitaria, 16, 20-24.

Subsecretaría de Planeamiento Educativo - Secretaría de Educación Ministerio de Educación (2015). Panorama de la Educación Rural en Argentina Área de Investigación y Evaluación de Programas Dirección Nacional de Información y Evaluación de la Calidad Educativa. Recuperado de:_https:// www.argentina.gob.ar/sites/default/files/boletin-12-1_12_15.pdf

Támara, E. (2018). Nociones generales de la enseñanza en la historia en los siglos XIX y XX. Quaestiones Disputatae - Temas de debate, 11, 131-147.

Ugalde, N. y Balbastre, F. (2013.) Investigación cuantitativa e investigación cualitativa: buscando las ventajas de las diferentes metodologías de investigación. Ciencias Económicas, 31(2),179-187. 